\title{
Corrigendum
}

\section{Intraoperative bacitracin irrigations for the prevention of surgical site infections-Consider the alternatives - CORRIGENDUM}

\section{Lina Meng PharmD ${ }^{1}$, Stan Deresinski MD² and Marisa Holubar MD, MS²}

${ }^{1}$ Stanford Health Care, Stanford, California and ${ }^{2}$ Division of Infectious Diseases and Geographic Medicine, Stanford University School of Medicine, Stanford, California

The above mentioned article contained an error regarding the volume for the sterile $10 \%$ povidone-iodine. The correct volume, $17.5 \mathrm{~mL}$ sterile $10 \%$ povidone-iodine, has been updated in the published article.

\section{Reference}

1. Meng L, Deresinski S, Holubar M. Intraoperative bacitracin irrigations for the prevention of surgical site infections-Consider the alternatives. Infect Control Hosp Epidemiol 2020;41: 831-832. doi: 10.1017/ice.2020.67 